\title{
Mathematics as a Science and Marine Activity Follow Each Other Throughout History
}

\section{Tatjana Stanivuk, Stipe Galić, Mia Bojanić}

From the earliest beginnings to the present day, there has always been a strong link between mathematics and shipping. Both started developing at about the same time, fulfilling the basic human needs to act and to be creative. The shipping industry has developed throughout the history relatively in line with the development of science, but there have been periods of stagnation in times of great crises and wars. Mathematics, as one of the oldest sciences, is used for various calculations in shipping from shipbuilding to trade, transportation, and management. The safety of navigation, improvement of accuracy in navigation, optimization of costs, higher earnings and profits for ship owners and employees pose only a fraction of maritime affairs, hardly accessible without the knowledge and application of mathematics. Therefore, the aim of this paper is to examine closely the historical development of mathematics and maritime affairs, and to show how the knowledge of mathematics can become a powerful tool in the hands of a seafarer.

\section{KEY WORDS}

$\sim$ Mathematics

$\sim$ Maritime

$\sim$ Historical development

$\sim$ Seafarer education

\section{INTRODUCTION}

The following paper is about mathematics and maritime affairs. Mathematics is an exact science which has evolved for thousands of years throughout history. Maritime activities, which are almost as old, allow a convenient and economical mode of transport of passengers and goods from one location to another.

The link between mathematics and maritime affairs is not reciprocal. While mathematical problems would be resolved even if the activity mentioned did not exist, without the application of mathematical models maritime affairs, as we know them today, would not exist.

An important fact is often forgotten: mathematical laws are all around us and follow us in all aspects of life, even though we often are unaware of them. Without a lot of mathematics, actions and processes, from the most basic to those complex ones, would not be possible.

The history and development of mathematics is not easy to summarize in a few pages, due to its being as old as humanity. The rapid development of modern science often leads us to the question of how it all started.

Maritime affairs stand out as a very important economic activity because they include all the activities related to the sea, thus contributing to the economic development and quality of our lives in general. The development, cohesion and progress of countries from the very beginning until the present day have largely depended on the use of sea routes. The importance of maritime affairs stems from the fact that the life and development of the modern world are directly conditioned by the international trade and transport of goods. Therefore, the sea as traffic route has a monopoly position.

Modern maritime affairs require an understanding of their formation and implementation, as well as the application of exact mathematical science in such a progressive and demanding 
technological progress of electronic and IT devices, such as those used on board ships.

\section{MATHEMATICS AS A SCIENTIFIC DISCIPLINE}

\subsection{Mathematics}

From the practical point of view, mathematics is a science that studies amount (numbers), structure, space and change. There are different viewpoints among mathematicians and philosophers as regards the definitions of mathematics (Steen, 1988).

Statisticians-mathematicians look for samples, and use them to create new assumptions. They check the accuracy of assumptions with the help of mathematical tools. When the mathematical model of observed events has been built, its application can provide an accurate approximation of future similar events. Using uncertainties and logic, mathematics was created from counting, calculation and measurement, and the systematic study of shapes and movement of physical objects. People used mathematics even before the appearance of the first written records about it. Solving mathematical problems may require years or even centuries of uninterrupted testing and research.

Firm arguments first appeared back in the ancient Greek mathematics, most in Euclid's elements. Mathematics developed slowly until the Renaissance, when mathematical innovations along with new scientific discoveries led to a sharp increase in the number of mathematical discoveries whose increase has continued until today. (Đula, 2014; Ramana, 2007; Schleicher and Lackmann, 2011). Since the initial researches of Giuseppe Peano, David Hilbert and others, which were related to the axiomatic definitions in the late nineteenth century, it has become common to observe mathematical research as establishing the veracity through vigorous seizure of selected axioms and definitions. Galileo Galilei said: “We can't understand the universe until we learn the language and grasp the symbols in which it is written". It is written in the mathematical language, and the letters are triangles, circles and other geometric figures, without which it is impossible to understand a single word. Without them, man will wander as in a dark labyrinth. Carl Friedrich Gauss called mathematics "Queen of all the sciences". Benjamin Peirce claims that mathematics is "Science that comes to the necessary conclusions". David Hilbert said about mathematics: "We are not talking about arbitrariness in any form. Mathematics is not like a game whose tasks are determined with arbitrarily written rules. In fact, it is a conceptual system of possessing internal necessity that may be so, and only so." Albert Einstein said that "As long as the mathematics laws are associated with reality, they are not certain; and as long as they are certain, they are not associated with reality". French mathematician Claire Voisin states: "There is a dose of creativity in mathematics, and that is all related to the movement that is being expressed" (Devlin, 1996; LaTorre et al.; du Sautoy, 2010).

\subsection{Geometry}

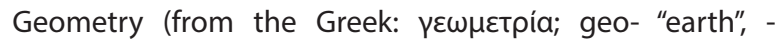
metron "measurement") is a branch of mathematics that deals with the problems of forms, sizes, and relations between figures, and properties of the space. In many early cultures, geometry appeared as an independent scientific discipline of lengths, surfaces and volumes. By the $3^{\text {rd }}$ century B.C., geometry was in the axiomatic form, as formed by Euclid, whose work "Euclid geometry" set the standards for many future generations (Turner et al., 1998). Archimedes gave ingenious techniques for calculating the surface area and volume, which in many ways preceded today's integral calculus. The field of astronomy, especially because it is related to showing the positions of stars and planets on the celestial sphere and describing the interrelationship and movement of celestial bodies, served as an important source of geometric problems in the following 1500 years. In the ancient world, they were considered as part of quadrivium, a subset of seven liberal arts which every man was expected to know.

With the introduction of the coordinate system by René Descartes and the concurrent development of algebra, a new stage of geometry started, considering the fact that since then, the shapes such as a plane curve could be analytically presented in the form of functions and equations. This played a key role in the appearance of infinitesimal calculus in the seventeenth century. Furthermore, the prospect theory proved that geometry was not just the measurement of characteristics of bodies, and it represented the origin of projective geometry. The subject of geometry is complemented by studying the internal structure of geometric bodies, which are a result of Euler and Gauss, and the creation of differential geometry.

In Euclid's time, there was no clear distinction between the real 3D space and coordinate system. Since the discovery of non-Euclidean geometry in the nineteenth century, the idea of space underwent a radical change and posed the question: Which coordinate system best describes the real 3D space? With the advent of formal mathematics, "space" has lost its intuitive content, so that today we must distinguish between physical space, geometric space and abstract spaces. The modern geometry considers new types of space, more abstract than the famous Euclidean space with which they hardly have anything in common. These spaces can be supplemented with additional bands that allow observation of length. Furthermore, the modern geometry is strongly associated with physics. One of the newest theories of physics, string theory, also comes from geometry.

While the visual nature of geometry makes it more accessible than other mathematical branches such as algebra 
or number theory, geometric language used within text differs significantly from its original meaning. Geometry is divided into planimetry, stereometry, trigonometry, analytic geometry and differential geometry (Hilbert, 1992; Kneebone, 1963; Renate et al., 2012).

\subsection{Trigonometry}

Trigonometry (from the Greek words trigōnon for triangle, and metron for measurement) is a branch of mathematics that studies the relationship between the length and angles in triangles. It was created in the $3^{\text {rd }}$ century B.C. from the geometric study of astronomical objects.

The astronomers then first noticed that the side lengths of a right triangle and the amounts of angles between the relative sides had fixed relations, and that is, if at least one side and one angle are known, the values of all the other sides and angles can be determined through logarithms. These calculations were soon defined as trigonometric functions and are still the foundations of pure and applied mathematics: the basic method of analysing these, e.g. Fourier transformation, or wave equation, using trigonometric functions to understand the cycle changes through the application in many different fields such as physics, mechanical and electrical engineering, music and acoustics, astronomy, ecology and biology. Trigonometry is also the basis of various tests.

To put it simply, trigonometry is associated with planar rectangular triangles. The possibility of application of oblique triangles exists but, due to the fact that any non-rectangular triangle can be divided so as to create two rectangular triangles, most of the problems can be reduced to calculations of rectangular triangles. Therefore, most of the applications relate to rectangular triangle. One exception to this rule is spherical trigonometry, science that studies triangles on the sphere, the surface of constant positive curvature, in elliptical geometry (basic part of astronomy and navigation). Trigonometry on the surface of negative curvature is hyperbolic trigonometry. The basics of trigonometry are often studied at school as a separate subject, or as part of basic mathematics.

The number of applications of trigonometry and trigonometric functions is very high. For example, triangulation technique is used in astronomy to measure the distance to close stars; in geography it is used to measure distances between landmarks, and it is also used in satellite navigation systems. The sine and cosines functions are the basis of the theory of periodic functions, such as those that describe sound and light waves.

The fields in which trigonometry and trigonometric functions are used, are: astronomy, terrestrial navigation, music theory, sound synthesis, acoustics, optics, electronics, probability theory, statistics, biology, medicine, pharmacy, chemistry, theory of numbers, seismology, meteorology, oceanography, many physical sciences, land surveying, architecture, economics, computer science, cartography, crystallography and game development (Bojanić, 2014; Mura, 1993; Sorić, 2014).

\section{MARITIME AFFAIRS}

\subsection{About Maritime Affairs in General}

Maritime affairs are activities that can be defined in the broad and narrow sense of the term (Schleicher and Lackmann, 2011). In the narrow sense, maritime affairs refer to the art of navigation and management skills, and maneuvering ships. In the broader sense, maritime affairs include all the activities related to the exploitation of the sea and coastal zone, in the direct or indirect way. The activities implied by the term maritime affairs are: trade and shipping, shipbuilding, port activities, tourism, naval activities, and the maintenance of ports, canals and security infrastructure. In addition to the above mentioned, there are many activities that would not be possible to run without maritime affairs; fisheries, aquaculture, various forms of exploitation, such as the exploitation of oil and natural gas.

The basic prerequisite for the existence of maritime affairs are waterways, among which the most important is the sea. It links all the continents and represents the cheapest form of transport because the construction infrastructure of a waterway is not required.

The states that do not have access to the sea are in various ways dependent on the countries that do. Thus, a permission to use the transit ports is a solution to be provided with the best possible contracts.

Maritime affairs include the knowledge of different activities and development of specialized skills, such as navigation. It is necessary to know the International Maritime Code; time, meteorology and weather forecasting, handling of ships and boats, handling equipment on deck, anchors and cables, work with ropes, engines, communications, sailing, survival at sea, search and rescue. Also, among the essential activities on board, cargo handling equipment and handling of dangerous cargo, conduct in emergencies, especially fire-fighting, should be mentioned.

There are many opinions about when the development of maritime affairs started, but the only certain thing is that it has been developing since the beginnings of mankind, and has arisen from the need of people to exploit the sea and coastal areas (Schleicher and Lackmann, 2011). According to the archaeological findings, the first simple boats were built in the Neolithic period.

The chronological development of maritime affairs can be divided into four phases: the first stage is maritime affairs in the ancient times to the $6^{\text {th }}$ century; the second phase includes the Middle Ages, from the $6^{\text {th }}$ to the $15^{\text {th }}$ century; the third phase is 
the time of great geographical discoveries, from the $15^{\text {th }}$ to $19^{\text {th }}$ century; the modern era of maritime affairs covers the period from the $19^{\text {th }}$ century to the present.

The first ancient civilizations that have developed maritime affairs were the Egyptians, Phoenicians, Cretans, and Greeks. After that, a significant role was played by the Romans, who were the only ones in history that managed to control the entire Mediterranean. Then began the development of shipping, shipbuilding, and fisheries. The most influential port of that era was Alexandria. In the ancient times, there were trade ships that sailed using wind power, and warships that were propelled by oars.

During the Middle Ages, especially after the discovery of the compass, maritime affairs flourished. Navigation was mainly based on the knowledge of the oceanographic characteristics and geographical features of the coast, with the help of nautical charts (terrestrial navigation).

During the great geographical discoveries, the focus of European and international maritime affairs moved from the Mediterranean to the Atlantic. The first Portuguese and Spanish colonies in the world were established, and it led to the development of intercontinental connections that changed the economic and social picture of the world and encouraged large population migrations.

\subsection{The Development of Modern Maritime Affairs}

At the very beginning of the development of maritime affairs, the main objectives were to find shorter and safer maritime routes, and to determine geographical location, and other important components of orientation and navigation, in the most reliable way (Poparić, 1932). One of the major issues in which all of Europe's leading scientists were engaged was the determination of longitude with direct application in maritime affairs. This problem was completely solved after 1728, when John Harrison invented the chronometer, clock that is accurate enough to be used as a portable time standard on vehicles, in this case on board a boat.

Great efforts were invested in finding the Northwest and Northeast Passages through the Arctic Sea, to cut the distance between Europe and the Far East and the Pacific coast of North America.

Although the knowledge of geographical and oceanographic features of newly discovered areas was much broader, the basic technology of maritime transport has not changed for thousands of years. The fixed assets were boats driven by sails.

The Industrial Revolution was characterized by the construction and application of the steam-powered ships. Steam-powered ships gradually replaced sailing ships because of better maneuverability capabilities and greater capacity, and also the ship's propeller appeared in 1827.

The excavation of the Suez Canal in 1869, and the excavation of the Panama Canal in 1914 had great significance for the development of modern maritime affairs.

Steamships allowed the establishment of a regular and relatively fast intercontinental connections in the passenger and freight traffic. With the tramp trade, liner trade also developed, which especially influenced the economic unification of certain parts of the coast. Great progress has also been made in the passenger maritime transport. In the $20^{\text {th }}$ century steampowered ships were gradually replaced with ships powered by diesel engines, and since the mid- $20^{\text {th }}$ century some warships and icebreakers have started using nuclear drive.

During the 20th century, freight traffic rapidly grew, especially the transportation of raw materials such as oil, coal, and iron ore. Therefore, larger ships were built, especially tankers and bulk-carriers, whose capacity exceeded 500,000 DWT.

Today, with daily developments in technology, new techniques are applied, integrated, and multi-modal transport develops, various specialized ships for the transport of general cargo (container, ro-ro ships, LASH ships) are built. Accordingly, ports and terminals also change.

\section{MATHEMATICS AND MARITIME AFFAIRS}

Applied mathematics is a branch of mathematics that deals with the application of mathematics in other scientific fields, inspires and finds use of new mathematical discoveries, which has led to the development of entirely new mathematical disciplines, such as statistics and game theory. Mathematicians also deal with pure mathematics, i.e. mathematics at the service of mathematics, without considering its application. There is no clear boundary between applied mathematics and pure mathematics, and often a practical application for discoveries that began as pure mathematics is found, e.g. in maritime affairs.

Maritime affairs can be defined as an activity including all actions either directly or indirectly connected with the sea. Maritime affairs include not only marine navigation and the conduct of ships, but they also combine the concepts of ships, workers, and companies across the shipbuilding industry to trade, transport and management. Mathematics, one of the oldest sciences, is used to calculate many, already mentioned items in shipping. The stability of a tossing boat, and financial budget applications in navigation are only a few problems that are solved with the help of mathematics. The safety of navigation, improving navigation accuracy, optimizing costs and how ship owners and employees in the maritime affairs make more revenue and profit, are only a fraction of maritime affairs which is 
navigation because, even if technology is considered reliable and accurate, one cannot always rely on it. After all, the background was human knowledge because without it, the development of technology would not have happened.

Options for a further development and improvement of maritime affairs are endless. Every day new ideas appear and are waiting for their realization. Still, maritime affairs are an activity for which it can safely be said that it will never disappear, because it is the most economical mode of transportation of different cargoes and passengers using all the waterways in the world without the need for construction of expensive infrastructure, which for example is required in rail or road transport.

\section{REFERENCES}

Bašić, Đ., (2008), Schoolships on the Eastern Adriatic Coast (Croatian School Ships "Margita", "Vila Velebita" and "Jadran"), Pomorski zbornik, 45 (2008) 1, pp. 229-258.

Bojanić, M., (2014), Mathematics in Maritime Affairs, Bachelor thesis, Split: University of Split, Faculty of Maritime Studies.

Devlin, K., (1996), The Science of Patterns: The Search for Order in Life, Mind and the Universe, New York: Scientific American Paperback Library.

Đula, J., (2014), Application of Trigonometry in Orthodromic Navigation, Bachelor thesis, Split: University of Split, Faculty of Maritime Studies.

Hilbert, D., (1992), Natur und Mathematisches Erkennen: Vorlesungen, gehalten 1919-1920 in Göttingen. Nach der Ausarbeitung von Paul Bernays, Basel, Birkhäuser., https://doi.org/10.1007/978-3-0348-8640-6
Kneebone, G. T., (1963), Mathematical Logic and the Foundations of Mathematics, An Introductory Survey, 1st edition, Dover Books on Mathematics.

LaTorre, D. R., Kenelly, J. W., Reed, I. B., Carpenter, L. R, Harris, C. R., (2011), Calculus Concepts: An Informal Approach to the Mathematics of Change, 5 th edition, Brooks Cole: Cengage Learning.

Mura, R., (1993), Images of Mathematics Held by University Teachers of Mathematical Sciences, Educational Studies in Mathematics, 25 (4), pp. 375-385.,

https://doi.org/10.1007/BF01273907

Poparić, B., (1932), Review of Maritime History, Zagreb: Matica hrvatska, pp. 132.

Ramana, B. V., (2007), Applied Mathematics, Tata McGraw-Hill Education.

Renate, T., Neunzert, H., Runge, I., (2012), A Life at the Crossroads of Mathematics, Science, and Industry, Springer.

Sautoy du, M., (2010), A Brief History of Mathematics: 1. Newton and Leibniz, BBC Radio 4, available at: http://www.bbc.co.uk/programmes/b00srz5b/episodes/ downloads, [accessed 3 March 2017.].

Schleicher, D. and Lackmann, M., (2011), What Is Mathematics?, An Invitation to Mathematics, From Competitions to Research, Berlin: Springer.,

https://doi.org/10.1007/978-3-642-19533-4

Sorić, M., (2014), Fundamentals of Trigonometry in Navigation, Bachelor thesis, Split: Faculty of Maritime Studies.

Steen, L. A., (1988), The Science of Patterns, Science, 240(4852), pp. 611-616., https://doi.org/10.1126/science.240.4852.611

Turner, M., Blackledge, J., Andrews P., (1998), Fractal Geometry in Digital Imaging, 1st edition, Orlando: Academic Press. 